\title{
Alzheimer's Disease Determination by a Dual Probe on Gold Nanourchins and Nanohorn Hybrids
}

This article was published in the following Dove Press journal:

International Journal of Nanomedicine

\section{Zhengguo Qiu, 'Qianhe Shen,' Chao Jiang, ${ }^{3} \mathrm{Li}$ Yao, ${ }^{4}$ Xiaopeng} Sun, ${ }^{5}$ Jing Li, ${ }^{6}$ Chongzhen Duan, ' Rui Li,' Xiuli Li, ', Subash CB Gopinath, (iD) ${ }^{7,8}$ Periasamy Anbu, ${ }^{9}$ Thangavel Lakshmipriya, ${ }^{8} \mathrm{Xu} \mathrm{Li}^{10}$

'Department of Anesthesiology, Affiliated Hospital of Shaanxi University of Traditional Chinese Medicine, Xianyang, Shaanxi, 7I 2000, People's Republic of China; ${ }^{2}$ Department of Anesthesiology, Xi'an GemFlower Changqing Hospital, Xi'an, Shaanxi, 710200, People's Republic of China; ${ }^{3}$ The Third Department of Neurology, The Second Affiliated Hospital of Xi'an Medical University, Xi'an, Shaanxi, 710038, People's Republic of China; ${ }^{4}$ Department of Neurology, The Hospital of Xidian Group, Xi'an, Shaanxi, 710077, People's Republic of China; ${ }^{5}$ Department of Otolaryngology, The Second Affiliated Hospital of Xi'an Medical University, Xi'an, Shaanxi, 7I0038, People's Republic of China; ${ }^{6}$ Department of Anesthesiology, The Second Affiliated Hospital of Xi'an Medical University, Xi'an, Shaanxi, 7I0038, People's Republic of China; ${ }^{7}$ Faculty of Chemical Engineering Technology, Universiti Malaysia Perlis (UniMAP), Arau, Perlis, 02600, Malaysia; ${ }^{8}$ Institute of Nano Electronic Engineering, Universiti Malaysia Perlis (UniMAP), Kangar, 01000, Malaysia; ' ${ }^{9}$ Department of Biological Engineering, College of Engineering, Inha University, Incheon, 402-75I, Republic of Korea;

${ }^{10}$ Department of Surgery and Anesthesiology, Xi'an Hospital of Traditional Chinese Medicine, Xi'an, Shaanxi, People's Republic of China

Correspondence: $\mathrm{Xu} \mathrm{Li}$ Email qzg2020@sina.com
Background: Alzheimer's disease (AD) is a neurodegenerative chronic disorder that causes dementia and problems in thinking, cognitive impairment and behavioral changes. Amyloidbeta $(\mathrm{A} \beta)$ is a peptide involved in $\mathrm{AD}$ progression, and a high level of $\mathrm{A} \beta$ is highly correlated with severe $\mathrm{AD}$. Identifying and quantifying $\mathrm{A} \beta$ levels helps in the early treatment of $\mathrm{AD}$ and reduces the factors associated with AD.

Materials and Methods: This research introduced a dual probe detection system involving aptamers and antibodies to identify A $\beta$. Aptamers and antibodies were attached to the gold $\mathrm{Au}$ ) urchin and hybrid on the carbon nanohorn-modified surface. The nanohorn was immobilized on the sensor surface by using an amine linker, and then a Au urchin dual probe was immobilized.

Results: This dual probe-modified surface enhanced the current flow during A $\beta$ detection compared with the surface with antibody as the probe. This dual probe interacted with higher numbers of $A \beta$ peptides and reached the detection limit at $10 \mathrm{fM}$ with $\mathrm{R}^{2}=0.992$. Furthermore, control experiments with nonimmune antibodies, complementary aptamer sequences and control proteins did not display the current responses, indicating the specific detection of $\mathrm{A} \beta$.

Conclusion: $A \beta$-spiked artificial cerebrospinal fluid showed a similar response to current changes, confirming the selective identification of $A \beta$.

Keywords: amyloid-beta, biomarker, nanomaterial, aptamer, antibody

\section{Introduction}

Alzheimer's disease (AD) is a chronic neurodegenerative disorder affecting older people that causes cognitive impairment, memory loss, changing personality and dementia. AD is irreversible and is becoming a serious health concern worldwide, with more than thirty-five million people affected. ${ }^{1,2}$ Behavioral and personality changes and the degree of memory loss are the first indications of AD. Brain imaging tests with magnetic resonance analysis, and computerized tomography have been utilized to identify $\mathrm{AD}^{3}{ }^{3}$ Recently, positron emission tomography (PET) was used to identify specific regions of the brain with decreased glucose metabolism, which helps to distinguish different brain degenerative diseases. Additionally, PET scans were used to identify cluster formation by amyloid plaques, which is closely associated with dementia caused by AD. However, these types of identification methods are expensive and uncomfortable for older people. Therefore, identification by blood-based biomarkers is an alternative way to diagnose $\mathrm{AD}$, making it cost-effective and convenient. ${ }^{4,5}$ Moreover, various biomarkers, such as microRNAs, proteins, peptides, antibodies and receptors, can 
identify $\mathrm{AD}$ and help to treat $\mathrm{AD}$ in its earlier stages. ${ }^{2,4,6}$ Since the condition caused by $\mathrm{AD}$ is irreversible, early detection of $\mathrm{AD}$ helps to establish a routine life for patients.

Aggregation and misfolding of amyloid-beta $(A \beta)$ is a potential mechanism in $\mathrm{AD}$ patients. ${ }^{7} \mathrm{~A} \beta$ monomers assemble into $\mathrm{A} \beta \mathrm{O}$ ( $\mathrm{A} \beta$ oligomers) and fibrils and are then distributed into the circulating blood or cerebrospinal fluid (CSF). ${ }^{1}$ The $\mathrm{A} \beta \mathrm{O}$ is neurotoxic and is highly correlated with severe $\mathrm{AD}$. Various studies have confirmed that the $\mathrm{A} \beta \mathrm{O}$ concentration is much higher in $\mathrm{AD}$ patients than in normal patients. ${ }^{1,8}$ Moreover, the $\mathrm{A} \beta \mathrm{O}$ level in CSF helps to predict the progression at earlier and periclinal stages of $\mathrm{AD}$. Therefore, using $\mathrm{A} \beta \mathrm{O}$ as a biomarker is not only useful for identification but also helps as a therapeutic target for AD. ${ }^{9}$ Various sensors, such as surface plasmon resonance, electrochemical sensors, enzyme-linked immunosorbent assays, RAMAN spectroscopy and fluorescent sensors, have been utilized to measure $A \beta O$ with the help of proteins, peptides, and antibodies. ${ }^{8,10-13}$ However, it is still challenging to identify $\mathrm{A} \beta \mathrm{O}$ with high specificity in biological fluids without nonspecific adsorption and interference. This research involved design of a combined dual probe with an aptamer and antibody on the surface of a gold $(\mathrm{Au})$ urchin to identify $\mathrm{A} \beta \mathrm{O}$ on a triangular electrochemical sensor.

Probe selection and immobilization on the sensor surface play a major role in achieving lower-level detection of the target molecule. There are various kinds of probes, such as RNA, DNA, aptamers, antibodies, peptides and enzymes, commonly used to detect analyte molecules. ${ }^{14}$ Among these, antibodies are more attractive and promising probes for the detection of biomolecules due to their selectivity and higher affinities for their targets. Due to the selectivity, an antibody was also used to detect the analyte even in a crude sample. On the other hand, aptamers are artificial antibodies that perform similar roles as antibodies in many biological applications. They can be artificially generated by the SELEX (systematic evaluation of ligands and exponential enrichment) process with the three simple steps of binding, separation and amplification. $^{15-17}$ Even though aptamers are widely applied in biological fields, work has been highly focused on developing biosensors due to the high specificity and selectivity of aptamers with their targets. Various aptamers have been generated for a wide range of targets for diagnosis and therapeutic purposes. ${ }^{18,19}$ In particular, aptamers and antibodies were used to implement sandwich assays to identify the target at a lower level and this indicate that sandwich assays with aptamers and antibodies displayed high performance levels. ${ }^{20,21}$ In most cases, an aptamer was used as the capture probe due to its strong binding to the target, and an antibody was used as the detection probe. However, this method of detection requires many steps and is time consuming. Therefore, this study introduces a dual probe consisting of an aptamer and antibody on an independent Au urchin surface to identify A $\beta O$. This probe was attached to the nanoform-decorated triangular sensor, and $\mathrm{A} \beta \mathrm{O}$ was detected at a lower level relative to a single platform.

Carbon nanohorns (CNHs) are carbon-based materials that have recently attracted considerable attention for various applications in different fields, where they are used in solar thermal collectors, supercapacitors, and fuel cells, and for photovoltaic and biomedical applications. ${ }^{22,23}$ In particular, CNHs are attractive in the biosensing field due to their high dispersibilities, high conductivities and large surface areas. Since CHNs improve the mechanical and electrical properties, researchers were encouraged to apply them in electrochemical sensors. ${ }^{24,25}$ Apart from that, the surface modification of CNHs is easily accomplished through the conical ends of CNHs with thiols, amines, and different types of pyrene and porphyrin derivatives. ${ }^{22}$ In the current research, a $\mathrm{CNH}$ was decorated onto a sensing surface to improve current flow and utilized to attach a dual probe (aptamer and antibody) to a $\mathrm{Au}$ urchin and identify $\mathrm{A} \beta \mathrm{O}$. The $\mathrm{CNH}$ was immobilized on the electrode surface by using the amine (3-aminopropyl)triethoxysilane (APTMS) linker, and then the dual probe was attached on the nanohorn through the amine on the APTMS with the Au urchin. This dual probe-attached surface was utilized to identify $A \beta O$ for the diagnosis of $\mathrm{AD}$.

\section{Materials and Methods Reagents and Biomolecules}

Ethanolamine, gold urchin, nanohorn, 16-mercaptoundecanoic acid, 3-(3-dimethylaminopropyl)carbodiimide (EDC), N-hydroxysulfosuccinimide (sulfo-NHS) and APTMS were received from Sigma Aldrich (USA). A $\beta$ (1-42) was purchased from DgPeptides Co., Ltd, China. Anti- A $\beta$ antibody was obtained from Abcam (England). The aptamer sequence (5'-SH-GCCTGTGTTGGGGCGGGTGCG) was reported by Tsukakoshi et al and synthesized commercially (Apical Scientific, Malaysia). ${ }^{26}$ Artificial CSF was prepared by mixing 
$3.0 \mathrm{mM} \mathrm{KCl}, 150 \mathrm{mM} \mathrm{NaCl}, 0.8 \mathrm{mM} \mathrm{MgCl}{ }_{2} \cdot 6 \mathrm{H}_{2} \mathrm{O}, 1 \mathrm{mM}$ phosphate and $1.4 \mathrm{mM} \mathrm{CaCl}_{2} \cdot 2 \mathrm{H}_{2} \mathrm{O} .{ }^{27,28}$

\section{Morphological Imaging of Au Urchin and Nanohorn}

Morphological images of the $\mathrm{Au}$ urchin, nanohorn and $\mathrm{Au}$ urchin-nanohorn hybrid were analyzed by field emission scanning electron microscopy (FESEM), field emission transmission electron microscopy (FETEM) and atomic force microscopy (AFM) or scanning AFM. Further energy dispersive X-ray (EDX) analysis was also conducted to confirm the elemental composition of the nanohorn and $\mathrm{Au}$ urchin.

\section{Preparation of Anti-A $\beta$ Antibody Conjugation with $\mathrm{Au}$ Urchin}

Anti-A $\beta$ antibody was conjugated on the surface of the $\mathrm{Au}$ urchin through 16-mercaptoundecanoic acid and EDCNHS linker. Briefly, $500 \mu \mathrm{L}$ of $\mathrm{Au}$ urchin was mixed with 16-mercaptoundecanoic acid (16-MDA, $5 \mathrm{mM}$ ) and kept for 1 hour at RT. After that, the unbound 16-MDA was separated by centrifugation. Subsequently, 16-MDAlinked Au urchin was activated by EDC and NHS (1:1) at $1 \mathrm{mM}$ and stirred at room temperature for $10 \mathrm{~min}$, and then the unbound EDC-NHS was removed by centrifugation. Finally, $10 \mu \mathrm{L}$ of $250 \mathrm{nM}$ anti-A $\beta$ antibody was added to the Au urchin mixture and stirred continuously for 2 hours. The unbound antibodies were separated by centrifugation (8000 rpm for $10 \mathrm{~min}$ ) followed by washing with distilled water three times to remove the unbound antibodies completely. The final antibody-Au urchin product was kept at 4 ${ }^{\circ} \mathrm{C}$ for further experiments.

\section{Preparation and Optimization of Dual Probes of $A \beta$ Antibodies and Aptamer- Conjugated Au Urchins}

To prepare a dual probe of aptamer and antibody on a $\mathrm{Au}$ urchin, the $\mathrm{Au}$ urchin antibody was first prepared as explained previously. After that, thiolated $A \beta$ aptamer was added to this solution (final concentration of 100 $\mathrm{pM}$ ) and kept at RT for $1 \mathrm{hr}$ to immobilize the aptamer on the remaining surface of the Au urchin. After that, the conjugated $\mathrm{Au}$ urchin-antibody-aptamer probe was separated by centrifugation and with three washings with distilled water. The same experiment was conducted with different aptamer concentrations $(1 \mathrm{nM}, 10 \mathrm{nM}, 100 \mathrm{nM}$ and $1 \mu \mathrm{M})$.

\section{Multiple Junction Triangle Dielectrode (MJTD) Fabrication}

Multiple junction triangle electrodes were fabricated with the traditional wet-etching procedure. First, the electrode pattern was designed by AutoCAD software. $^{29,30}$ The sensor surface was organized by two electrodes with multiple junction triangles at equal micro gap distances. The following steps were used to prepare the electrode. (i) A silicon wafer substrate was thermally oxidized at $500^{\circ} \mathrm{C}$ to form a silicon dioxide $\left(\mathrm{SiO}_{2}\right)$ layer; (ii) Aluminum was coated using a thermal evaporator; (iii) a $2000 \mathrm{~nm}$ thick layer of positive photoresist was applied by a spin-coater and then soft-baked at $90^{\circ} \mathrm{C}$ for $1 \mathrm{~h}$; (iv) UV-light exposure was carried out for $10 \mathrm{~s}$ to transform the desired pattern on the photoresist; (v) the electrode was dipped in the developing solution to remove the desired area and then subjected to hardbaking at $110^{\circ} \mathrm{C}$ for $1 \mathrm{~min}$; (vi) the electrode was immersed in Al-etching solution and then washed with distilled water and acetone. The final product was kept in a dry place for further experiments.

\section{$A \beta$ Oligomer $(A \beta O)$ Preparation}

To obtain the $A \beta$ monomer, an $A \beta$ solution with a concentration of $2 \mathrm{mg} / \mathrm{mL}$ was suspended in $1 \mathrm{mg} / \mathrm{mL}$ $100 \%$ HFIP (1,1,1,3,3,3-hexafluoroisopropanol) and this mixture was incubated overnight at room temperature under shaking conditions. HFIP worked as a hydrogen bond breaker to remove the pre-existing structural inhomogeneity of $A \beta$. The next day, the HFIP solvent was evaporated by treating the mixture under $\mathrm{N}_{2}$ gas. Then, HFIP-treated $A \beta$ was suspended in $100 \mu \mathrm{L}$ of $1 \mathrm{mM}$ $\mathrm{NaOH}$ and diluted to $100 \mu \mathrm{M}$ in PBS buffer to obtain the monomer. Further, the $A \beta$ monomer was kept at $37{ }^{\circ} \mathrm{C}$ overnight to form the $\mathrm{A} \beta$ oligomer $(\mathrm{A} \beta \mathrm{O})$, and then the formed $A \beta O$ was separated from the insoluble aggregates by centrifugation at $10,000 \mathrm{x} \mathrm{g}$ for $15 \mathrm{~min}$. All the prepared solutions were aliquoted immediately and stored at $-20{ }^{\circ} \mathrm{C}$ for further use.

\section{Detection of $A \beta O$ by Antibody or Antibody-Aptamer or a Dual Probe of Aptamer and Antibody \\ $\mathrm{A} \beta \mathrm{O}$ was detected on the MJTD surface and the following three methods were compared.}




\section{Detection of $A \beta O$ by $A u$ Urchin-}

\section{Antibody}

In this method, an anti-A $\beta$ antibody-modified $A u$ urchin was attached to the sensing electrode surface through the APTMS linker. First, the surface was treated with $1 \%$ $\mathrm{KOH}$ for $10 \mathrm{~min}$, and then APTMS-nanohorn was added and incubated for $3 \mathrm{~h}$. After washing the surface with ethanol (30\%), antibody-Au urchin was added and incubated for $1 \mathrm{~h}$. Then, the electrode was washed three times with PBS to eliminate the unbound aptamer. After that, the excess sensing electrode was covered with $1 \mathrm{mg} / \mathrm{mL}$ diluted PEG-NH${ }_{2}$. Different concentrations of $\mathrm{A} \beta \mathrm{O}$ were allowed to interact with the immobilized antibody. The current response was noted before and after each immobilization process.

\section{Detection of $A \beta O$ by Au Urchin-Antibody Aptamer (Two Step)}

In this method, $\mathrm{A} \beta \mathrm{O}$ was detected by an aptamer and antibody with a two-step process. The following steps were involved in this detection strategy: (i) the surface was modified with APTMS nanohorns; (ii) Au urchin antibody was immobilized on the APTMS nanohorns; (iii) the remaining areas were blocked with $1 \mathrm{mg} / \mathrm{mL}$ diluted PEG$\mathrm{NH}_{2}$; (iv) different concentrations of aptamer were added; and (v) different concentrations of $\mathrm{A} \beta \mathrm{O}$ were added to determine the limit of detection.

\section{Detection of $A \beta O$ by Au Urchin-Antibody Aptamer (Single Step)}

In this method, $\mathrm{A} \beta \mathrm{O}$ was detected by aptamer and antibody with a single step attachment. The following steps were involved in this detection strategy: (i) the surface was modified with APTMS nanohorns; (ii) the Au urchin antibody was immobilized on APTMS nanohorns; (iii) the remaining areas were blocked with $1 \mathrm{mg} / \mathrm{mL}$ diluted PEG$\mathrm{NH}_{2}$; (iv) a dual probe of antibody-aptamer was added; and (v) different concentrations of $\mathrm{A} \beta \mathrm{O}$ were added to determine the limit of detection.

\section{Selective Detection of $A \beta O$}

To identify specific $\mathrm{A} \beta \mathrm{O}$ detection, the following control experiments were conducted. The experiments were performed (i) without $\mathrm{A} \beta \mathrm{O}$; (ii) with nonimmune antibody and complementary aptamer sequence; and (iii) with $\alpha$ synuclein instead of $A \beta O$. The current responses in control experiments were compared with those for the specific $\mathrm{A} \beta \mathrm{O}$ detection. To determine the detection of $\mathrm{A} \beta \mathrm{O}$ in a real-life sample, different $\mathrm{A} \beta \mathrm{O}$ concentrations (0.01,
0.1, 1 and $10 \mathrm{pM}$ ) were spiked in artificial CSF and dripped on a dual probe immobilized surface. The other experimental setup was used as described above.

\section{Results and Discussion}

Figure 1 shows a schematic diagram for $\mathrm{A} \beta \mathrm{O}$ determination on a nanohorn-modified dielectrode surface. Three different probe surfaces are compared to identify $A \beta O$, which includes only Au-urchin conjugated antibody, antibodyaptamer (two-steps) and a dual probe with antibody and aptamer (single step). In the first experiment, a Au-urchin antibody was attached to the nanohorn-modified surface through an APTMS linker. APTMS-modified nanohorns were attached to the dielectrode by reacting the amine on the nanohorn and the $\mathrm{OH}$ on the electrode surface. Then, the Au-antibody was conjugated onto the electrode through the electrostatic interactions of amine on the nanohorn with the $\mathrm{Au}$ surface or amine on the nanohorn with $\mathrm{COOH}$ on the antibody. $\mathrm{A} \beta \mathrm{O}$ was detected on these antibody-modified surfaces. In the second experiment, using the same method, Au-urchin antibody was immobilized first. Then, an aptamer was added until the saturation point was attained. This thiollinked aptamer bound to the remaining gold surface and was used to detect $\mathrm{A} \beta \mathrm{O}$. In the last experiment, before the immobilization of the Au urchin antibody, the aptamer was attached to the remaining Au urchin (aptamer and antibody on Au-urchin) and then immobilized on a nanohornmodified surface. A $\beta O$ detection on this surface was compared with the above two methods.

\section{Characterization of Nanohorn and Nanohorn-Au Urchin with FESEM and EDX}

The surface structure of the Au urchin was initially analyzed by AFM and FETEM. Figure 2A shows AFM observations of an intact particle with uniformity. The surface scan of the $\mathrm{Au}$ urchin clearly displayed the expected size of approximately $55 \mathrm{~nm}$ (Figure 2B). Figure $2 \mathrm{C}$ is the FETEM image of the Au urchin, distributed uniformly with an urchin shape. The EDX result confirmed the presence of $\mathrm{Au}$ at a $65 \%$ level (Figure 2D and E). Furthermore, the morphologies of Au-urchin, nanohorn and antibody-Au urchin immobilized on the sensing electrode were observed by FESEM analysis.

Figure $3 \mathrm{~A}$ and $\mathrm{B}$ shows the FESEM image of the $\mathrm{Au}$ urchin, which is uniformly displayed in the $3 \mathrm{D}$ shape of urchin, and the related EDX confirmed the presence of 


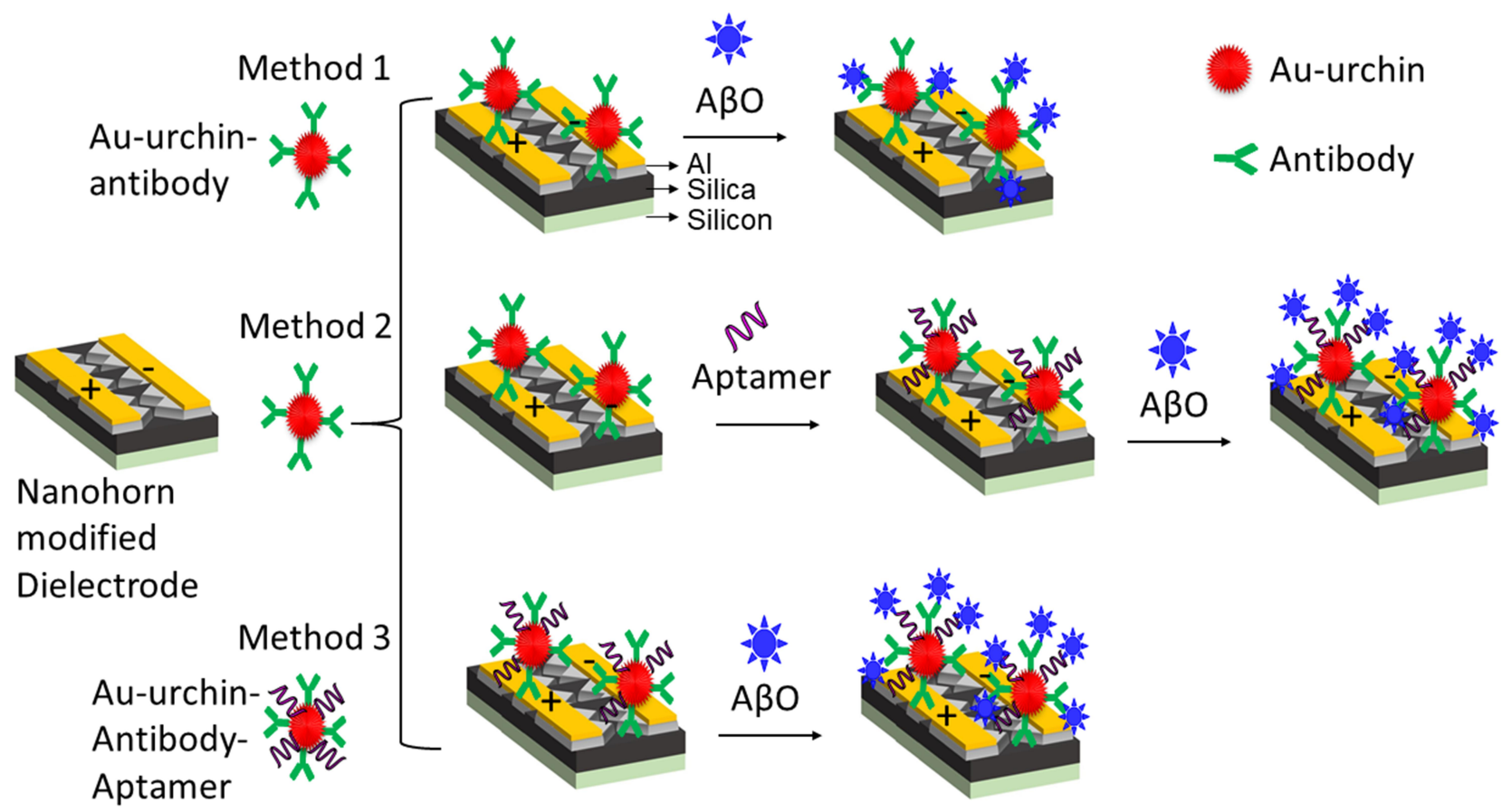

Figure I Schematic illustration of $A \beta O$ determination on a nanohorn-modified dielectrode. Three methods of $A \beta O$ detection were compared with the probes of (i) Auurchin antibody; (ii) Au-urchin antibody-aptamer; and (iii) dual probe of aptamer and antibody on Au urchin.
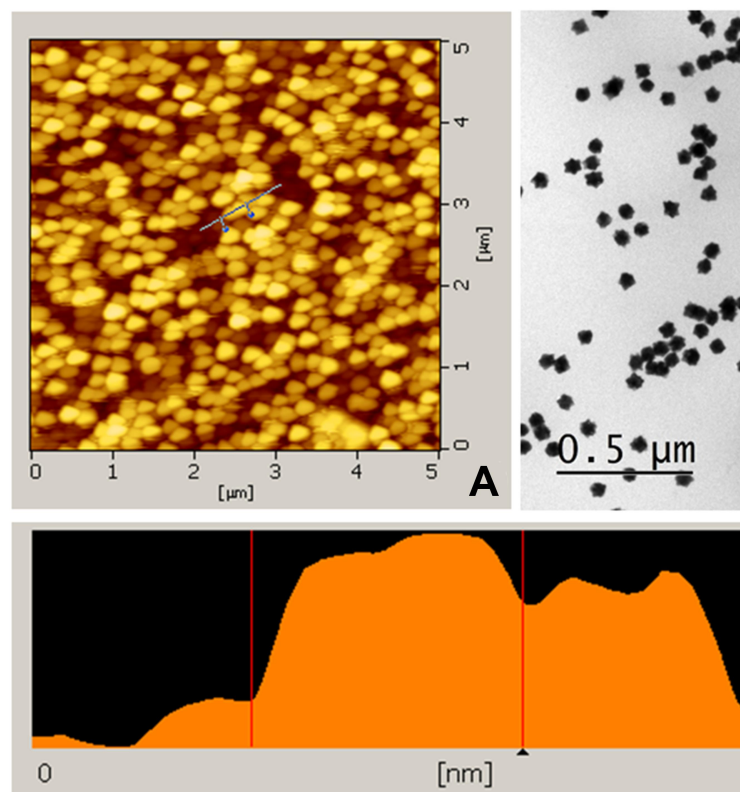

$[\mathrm{nm}]$

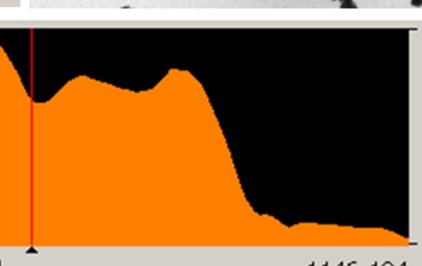

1146.184
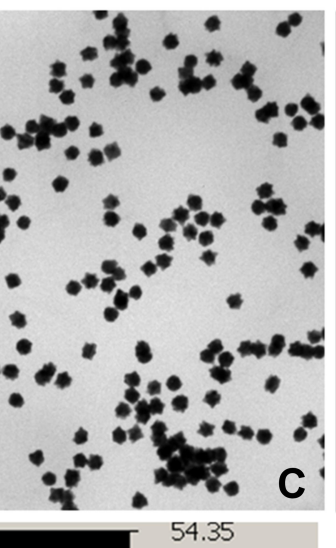

$[\mathrm{nm}]$

15.45

B

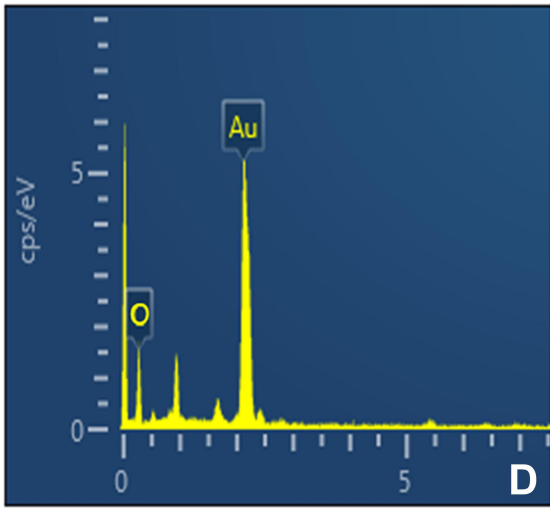

\begin{tabular}{|c|c|c|c|}
\hline Element & Wt\% & $\begin{array}{c}\text { Wt\% } \\
\text { Sigma }\end{array}$ & $\begin{array}{c}\text { Atomic } \\
\%\end{array}$ \\
\hline $\mathbf{O}$ & 35.64 & 1.21 & 90.08 \\
\hline Au & 64.36 & 1.21 & 9.92 \\
\hline Total & 100.00 & & 100.00 \\
\hline
\end{tabular}

Figure 2 Surface analysis by EDX. (A) AFM image of Au urchin; (B) surface of Au urchin-attached wafer; (C) FETEM image of Au urchin; (D) EDX analysis of Au urchin; (E) elemental composition of Au urchin. EDX results confirm the presence of carbon and gold on the immobilized surface.

$100 \%$ gold. Figure 3C and D insets are FESEM images of the nanohorn, displaying a circular shape of the horn on the surface with a uniform distribution. The EDX result for the nanohorn showed that the major elements were $\mathrm{C}$ at
$89 \%$ and $\mathrm{O}$ at $5.9 \%$. Figure $3 \mathrm{E}$ and $\mathrm{F}$ displays the FESEM image of the antibody-Au-urchin conjugated nanohorn immobilized on the electrode surface. The figure shows a Au urchin similar to the nanohorn, but a spike on the nanohorn was 


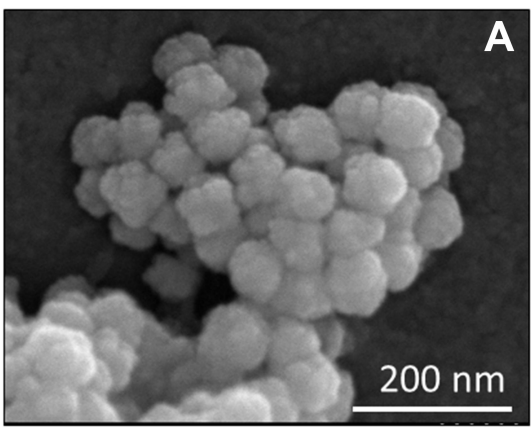

B

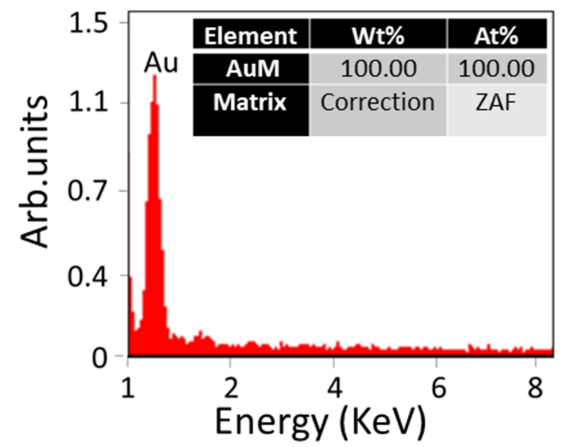

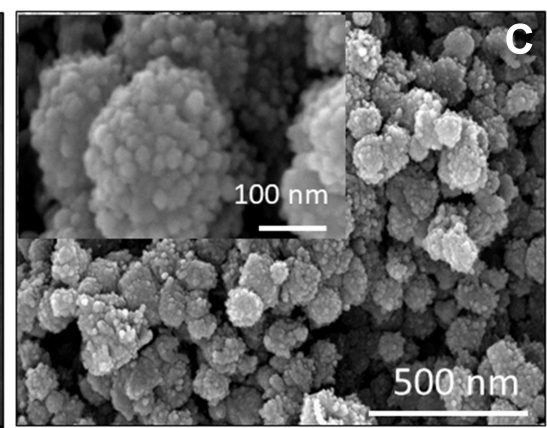

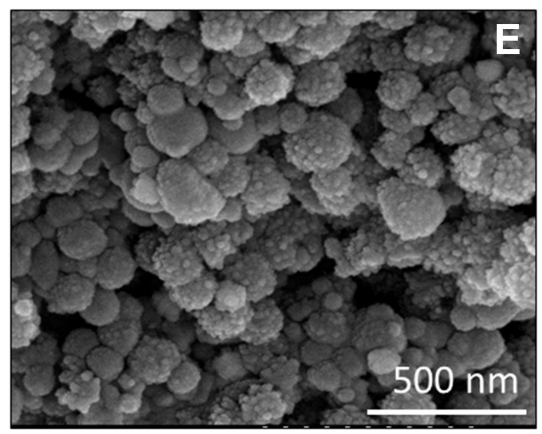

D

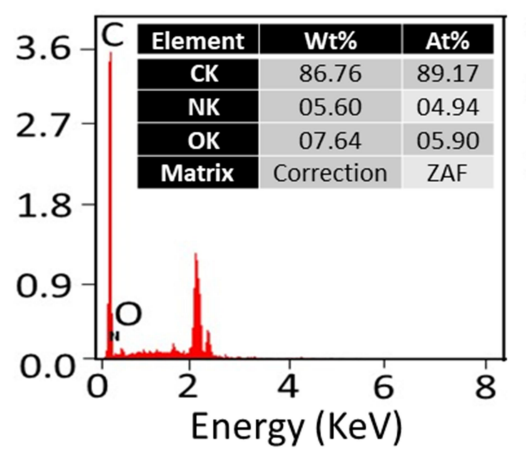

$\mathbf{F}$

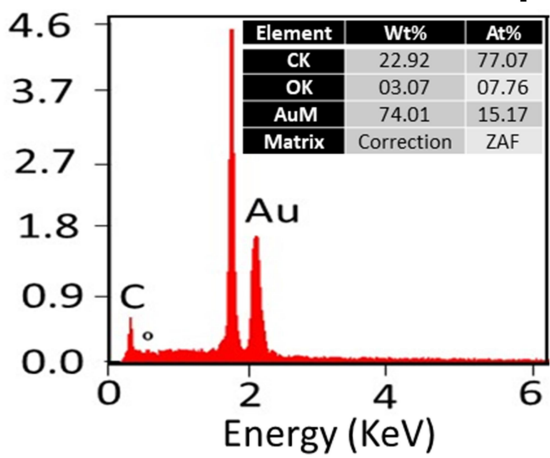

Figure 3 Surface morphology of the nanomaterial-modified electrode. (A) FESEM image of Au urchin; (B) EDX analysis of Au urchin; (C) FESEM image of nanohorn; Figure inset is at higher magnification. (D) EDX analysis of nanohorns; (E) FESEM image of Au-urchin antibody on nanohorns; (F) EDX analysis of Au-urchin antibody on nanohorns. EDX results confirm the presence of carbon and gold on the immobilized surfaces.

noticeable. Furthermore, the EDX results confirmed the presence of $77 \% \mathrm{C}$ and $15 \% \mathrm{Au}$. This result confirms the binding of antibody-conjugated Au-urchin on the electrode surface. This electrode surface was utilized to determine A $\beta O$.

\section{Probe Immobilization on a}

Nanohorn-Modified Dielectrode Surface:

\section{Target Interaction}

Three different methods of probe immobilization, antibody, antibody-aptamer and antibody, and aptamer as a dual probe on $\mathrm{Au}$ urchin, were compared for efficient detection of $\mathrm{A} \beta \mathrm{O}$. Figure $4 \mathrm{~A}$ displays the current response of antibody immobilization on the nanohorn-modified electrode. With each step, the current response was recorded to confirm the immobilization process. The $\mathrm{KOH}$-treated bare dielectrode showed a current level of 5 E-07 A. After modifying the surface with the APTMS nanohorn, the surface current was increased to 1.24E-05 A. Furthermore, when the Au urchin antibody was added, the current response was increased to $3.57 \mathrm{E}-05 \mathrm{~A}$. This increase in current occurred due to the interaction of APTMS on the nanohorns with $\mathrm{COOH}$ in the antibody and Au urchin with the APTMS molecule. In general,
APTMS is a potential linker to attach antibodies to the sensing surfaces. Proper orientation of the antibody attachment on APTMS enhances the performance of the sensor. A nanohorn was utilized here to attach a higher number of APTMS molecules on the electrode, which automatically increased the number of attached antibodies on the electrode surface. In addition, the nanohorn improved the electrical flow upon binding biomolecules on the sensing surface. Apart from that, on the surface of the Au urchin, a higher number of antibodies was attached, which also enhanced antibody attachment on the electrode surface. After the surface was modified by antibody, the excess APTMS surface was covered with PEG-NH $\mathrm{N}_{2}$. APTMS attracts other biomolecules through electrostatic interactions, which leads to false positive detection of $\mathrm{A} \beta \mathrm{O}$. Therefore, it is mandatory to cover the excess APTMS; here, PEG polymer was used as the blocking agent. Various studies have proven that surface modification with PEG polymers gives a proper arrangement of biomolecules on sensing surfaces and reduces the signal-to-noise ratio. $^{20,31,32}$ This antibody-modified surface (method 1) was used to compare the detection of $A \beta O$ with those of other methods described below. 

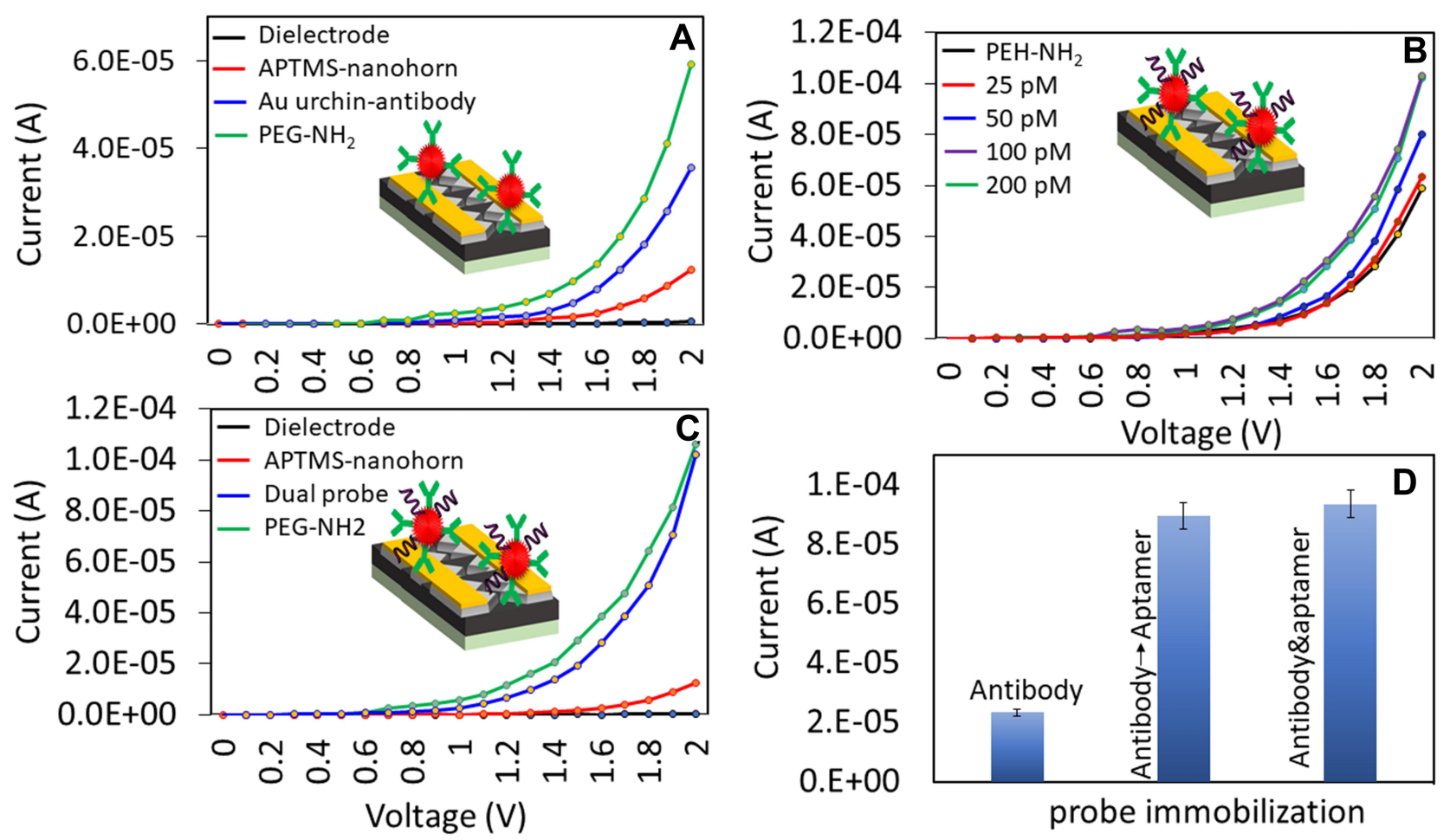

Figure 4 Comparison of probe immobilization on nanohorn-modified electrodes. (A) Au urchin antibody immobilization on APTMS-nanohorn; (B) aptamer titration on Auurchin-antibody attached electrode; (C) dual probe of antibody-aptamer immobilization on APTMS-nanohorn; Figure insets are diagrammatic. (D) Comparison of current changes with different probe immobilizations. The dual probe of the aptamer and antibody shows the highest current response.

In the second case (method 2), Au antibody was attached as explained previously, and then aptamer was added until the surface was saturated. Thiolated aptamers can attach to the excess surface area of Au urchins. Since the antibody is large, it automatically forms gaps between antibodies when attached to the surface of the Au urchin. Our idea was to fill the gaps with the smaller sized aptamer. As shown in Figure 4B, when 25 pM aptamer was added, little current was noted (brown line). Increasing the concentration to $50 \mathrm{pM}$ changed the current from 1.02 E-04 to 8.01 E-05 A. This result confirmed the binding of the aptamer on the surface of the Au-urchin. Furthermore, upon increasing the aptamer concentration to 100 and $200 \mathrm{pM}$, clear current changes were noted. It was further noticed that aptamer binding was saturated at $200 \mathrm{pM}$. This antibody-aptamer-modified surface was used to compare the detection of $\mathrm{A} \beta \mathrm{O}$ with those by other methods.

In the last method (method 3), an aptamer was attached to the surface of the Au urchin antibody. After attaching the antibody to the Au urchin, $200 \mathrm{pM}$ aptamer was added to cover the excess surface. This helped to reduce the steps and time of the probe immobilization process, and the aptamer could attach more readily to the Au urchin surface in solution than to the surface. Figure $4 \mathrm{C}$ displays a dual probe with an antibody aptamer on a Au urchin immobilized on a nanohorn-modified electrode surface. After attaching the APTMS nanohorn (red line), the dual probe was directly added, and the observed current increased from $1.24 \mathrm{E}-05$ to $1.06 \mathrm{E}-04 \mathrm{~A}$. This increase in current confirmed the binding of the probe on the sensing electrode surface. Compared to the previous method of probe immobilization, the antibody probe showed a current difference of $2.34 \mathrm{E}-05 \mathrm{~A}$, the antibody followed by aptamer immobilization showed a current difference of 8.96 E-05 $\mathrm{A}$, and with the antibody-aptamer as a dual probe, the current difference was 9.36E-05 A (Figure 4D). It was clearly concluded that when aptamer was added with antibody, the current level increased approximately 4 times more that with the case of antibody alone. It was also noted that there was little difference between method 2 (antibody and then aptamer) and method 3 (dual probe of aptamer and antibody). From this result, it was concluded that the dual probe method is an efficient immobilization method for attaching both aptamers and antibodies simultaneously on sensing surfaces. This probing system also 
possibly interacts with a higher number of $\mathrm{A} \beta \mathrm{O}$ s and enhances detection.

\section{Comparative Detection of $A \beta O$ on Different Probe Immobilized Electrode Surfaces}

Detection of $\mathrm{A} \beta \mathrm{O}$ at a $1 \mathrm{nM}$ concentration was compared for three different probe-immobilized electrode surfaces (methods 1,2 and 3). $A \beta O$ was dripped onto the probe-attached surface, and the current changes were noted. On the antibody-modified surface, $1 \mathrm{nM} A \beta O$ was added and the current response changed from 3.57 E-05 to 5.68 E-06 A (Figure 5A). A similar amount of $1 \mathrm{nM} \mathrm{A} \beta \mathrm{O}$ was added to the antibodyand aptamer-modified surfaces, and the current changed from 1.06 E-04 to 7.22 E-06 A (Figure 5B). Finally, the current was changed from $1.02 \mathrm{E}-04$ to $3.98 \mathrm{E}-07 \mathrm{~A}$ when $\mathrm{A} \beta \mathrm{O}$ was dripped onto the dual probe of the aptamer and antibodymodified surface (Figure 5C). The differences in currents noted for $1 \mathrm{nM} \mathrm{A} \beta \mathrm{O}$ detection were $2.9 \mathrm{E}-06 \mathrm{~A}$ in method 1 , $9.878 \mathrm{E}-06$ in method 2 and $10.1 \mathrm{E}-06 \mathrm{~A}$ in method 3 (Figure 5D). This result indicated that the dual probe increased the current flow with the same concentration of $A \beta O(1 \mathrm{nM})$ due to the binding of $\mathrm{A} \beta \mathrm{O}$ with the aptamer and antibody.

\section{Limit of Detection of $A \beta O$ : A Linear}

\section{Regression Analysis}

To calculate the limit of $\mathrm{A} \beta \mathrm{O}$ detection, different dilutions of $\mathrm{A} \beta \mathrm{O}(0.01$ to $100 \mathrm{pM})$ were individually dripped onto probe-modified surfaces. Figure $6 \mathrm{~A}$ shows the current changes observed after dripping $\mathrm{A} \beta \mathrm{O}$ on antibody-aptamermodified surfaces (method 2). Upon adding $10 \mathrm{fM} \mathrm{A \beta O}$, the current was changed from 1.06E-04 to $2.8 \mathrm{E}-05 \mathrm{~A}$. This result shows the interaction of $0.01 \mathrm{pM} \mathrm{A \beta O}$ with the antibody and aptamer. With further increases in the concentrations of $\mathrm{A} \beta \mathrm{O}$ to $0.1,1,10$, and $100 \mathrm{pM}$, the current flows gradually decreased to $1.64 \mathrm{E}-05,1.33 \mathrm{E}-05,8.85 \mathrm{E}-06$ and $7.34 \mathrm{E}-06 \mathrm{~A}$, respectively. It was noticed that concentrations of 10 and $100 \mathrm{pM}$ showed saturation in the current changes.

A similar experiment was conducted on an aptamerantibody dual probe immobilized electrode surface (method 3) (Figure 6B). In this case, after adding $10 \mathrm{fM} \mathrm{A} \beta \mathrm{O}$, the current was changed from $1.02 \mathrm{E}-04$ to $2.35 \mathrm{E}-05 \mathrm{~A}$. This result confirmed the interaction of $0.01 \mathrm{pM}$ of $\mathrm{A} \beta \mathrm{O}$ with the antibody and aptamer. With further increases in the concentrations of $\mathrm{A} \beta \mathrm{O}$ to $0.1,1,10$, and $100 \mathrm{pM}$, the current flows gradually decreased to $1.59 \mathrm{E}-05,1.15 \mathrm{E}-05,5.03 \mathrm{E}-06$ and 2.97 E-06 A, respectively. When comparing these two
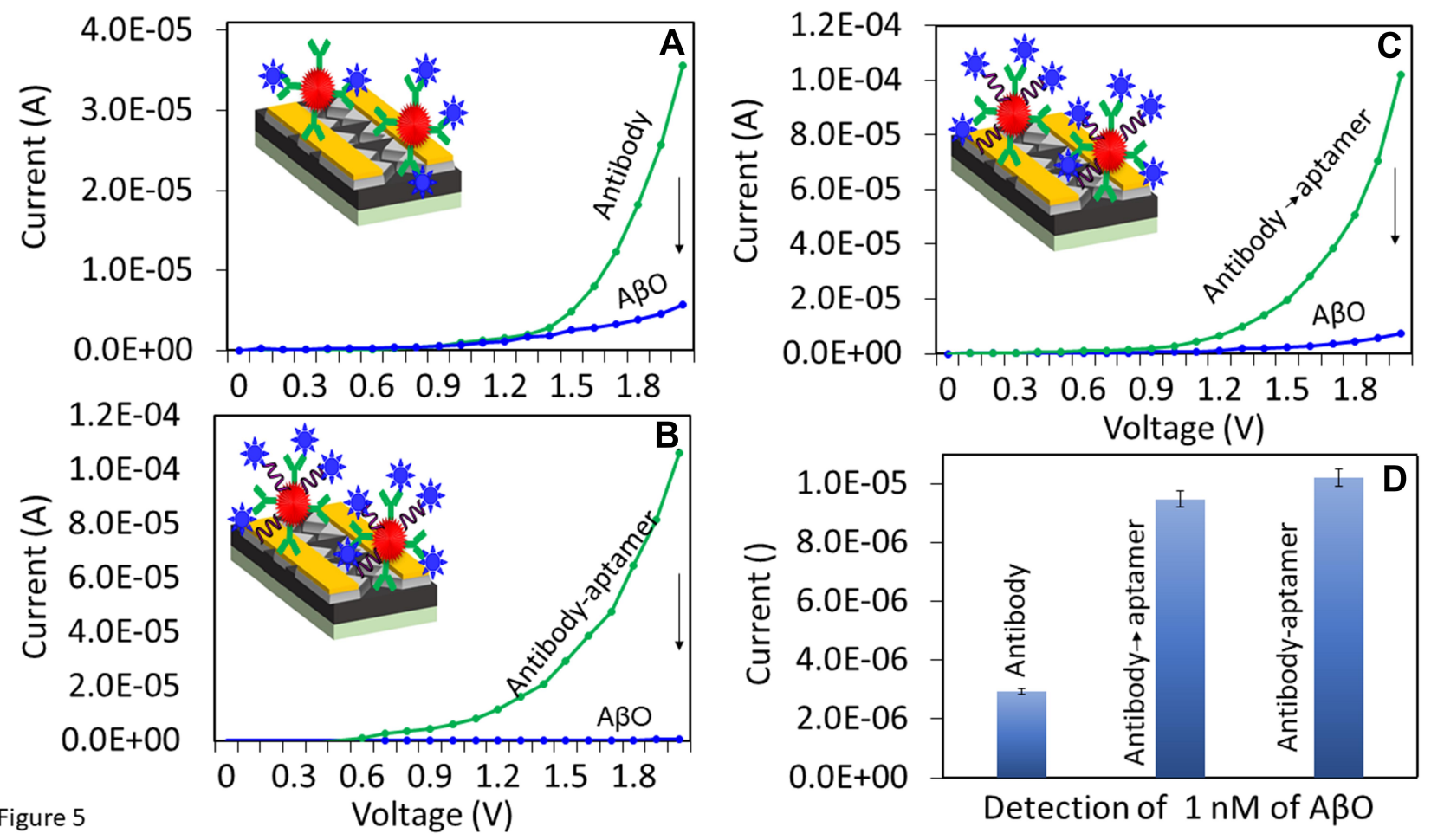

Figure 5 Comparison of detection of I nM ABO on (A) Au urchin antibody immobilized electrode; (B) antibody-aptamer immobilized electrode; (C) dual probe of antibody-aptamer immobilized electrode; Figure insets are diagrammatic. (D) Comparison of current changes of $A \beta O$ detection with different probes. A dual probe with an aptamer and antibody shows the highest current response. 

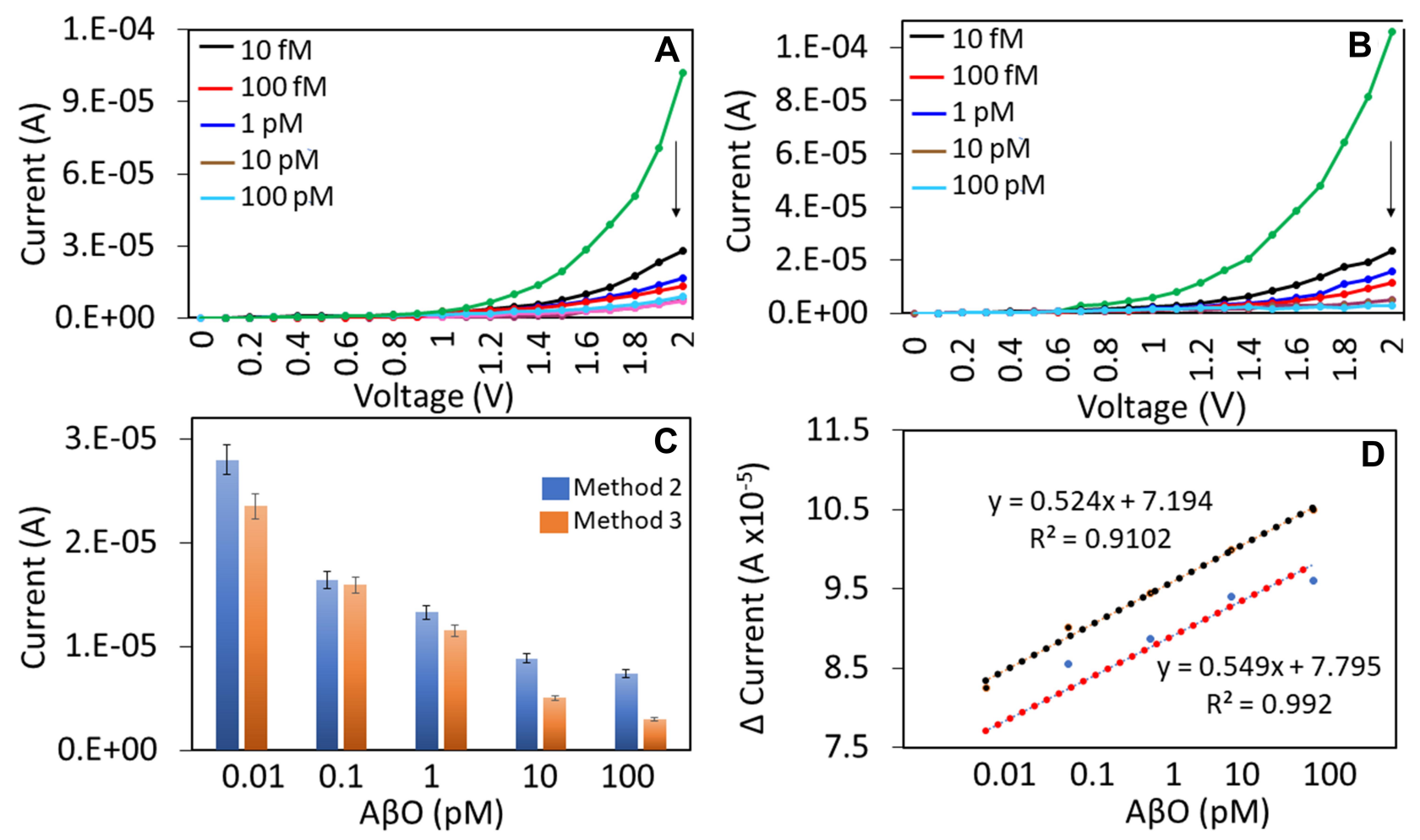

Figure 6 Different concentrations of A $\beta O$ by titration (0.0I-100 pM) on (A) Antibody-aptamer immobilized electrode; (B) dual probe of antibody-aptamer immobilized electrode; (C) comparison of current changes with $A \beta O$ titration, dual probe shows the highest current response with all $A \beta O$ concentrations; (D) difference in current changes in $\mathrm{A} \beta \mathrm{O}$ determination were plotted in an Excel sheet and used to calculate the detection limit. The detection limit was found to be 10 fM by both methods.

detection methods for $\mathrm{A} \beta \mathrm{O}$ identification, method 3 shows a higher current response than method 2. Furthermore, the saturation point was $100 \mathrm{pM}$ with the dual probe, while it was $10 \mathrm{pM}$ with the antibody-aptamer probe surface (Figure 6C). These results indicated that the dual probe method attracted a higher number of $\mathrm{A} \beta \mathrm{O}$ s and increased the current responses. The current difference was calculated for each $\mathrm{A} \beta \mathrm{O}$ concentration (in methods 2 and 3 ) and plotted in an Excel sheet to calculate the limit of detection. As shown in Figure 6D, both methods showed the same detection limit of

Table I Comparing Detection of $A \beta$ with Available Methods

\begin{tabular}{|c|c|c|c|c|c|}
\hline Sensor & Target & Probe & Detection limit & Linear range & Reference \\
\hline Smart near infrared fluorescence & $A \beta \mid-42$ & m-electron chain for $A \beta$-plaques & $0.027 \mu \mathrm{M}$ & - & (33) \\
\hline EIS sensor & $A \beta-40$ & Aptamer & $\sim 20 \mathrm{fM}$ & $0.1 \mathrm{pg} / \mathrm{mL}-10 \mu \mathrm{g} / \mathrm{mL}$ & (34) \\
\hline Electrochemical sensor & $A \beta \mid-42$ & Aptamer & $3.5 \times 10^{-14} \mathrm{~mol} / \mathrm{L}$ & $1 \times 10^{-13}$ to $1 \times 10^{-8} \mathrm{~mol} / \mathrm{L}$ & (35) \\
\hline Electrochemical sensor & $\mathrm{A} \beta \mathrm{O}$ & Aptamer-antibody & $100 \mathrm{pM}$ & $0.5-30 \mathrm{nM}$ & (8) \\
\hline Impedance sesnor & $\mathrm{A} \beta \mathrm{O}$ & Cellular prion protein & $0.1 \mathrm{pM}$ & $10^{-8}$ to $10^{4} \mathrm{nM}$ & (36) \\
\hline Amperometric sensor & $A \beta$ & Aptamer & $0.002 \mathrm{pM}$ & $0.1 \mathrm{pM}-10 \mathrm{nM}$ & (37) \\
\hline SERS & $A \beta$ & Sialic acid & I pM & I pM-II.5 nM & (38) \\
\hline Colorimetric assay & $\mathrm{A} \beta \mathrm{O}$ & $\operatorname{PrP}$ & $20 \mathrm{nM}$ & $20-100 \mathrm{nM}$ & (39) \\
\hline Fluorescent sensor & $A \beta$ & CRANAD-2 & $38 \mathrm{nM}$ & - & (40) \\
\hline Electrochemical sensor & $\mathrm{A} \beta \mathrm{O}$ & Aptamer-antibody & $10 \mathrm{fM}$ & $0.01-100 p M$ & This work \\
\hline
\end{tabular}

Abbreviations: EIS, electrode-insulator-semiconductor sensor; FET, field effect transistor. 

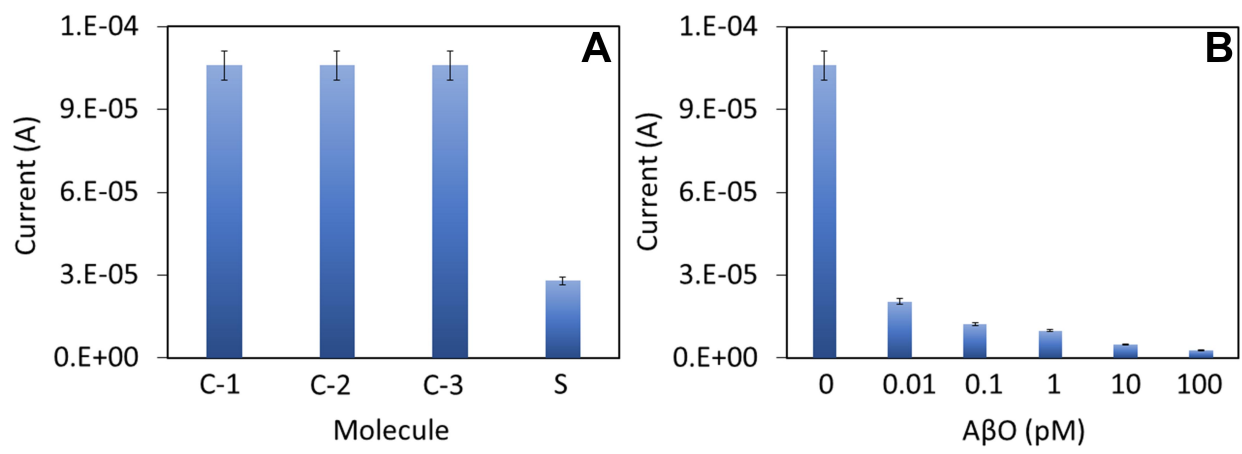

Figure 7 Selective detection. (A) A $\beta O$ was identified with C-I (no A $\beta O$ ), C-2 (with nonimmune and complementary aptamers), and C-3 (with control protein). No significant changes were noted in any of the above three control experiments compared with the specific interaction(s) of $A \beta O$ with its antibody and aptamer. (B) Spiking experiment. Different $A \beta O$ concentrations $(0.01,0.1$, I and I0 pM) in artificial CSF were dripped independently on dual probe-modified surfaces. CSF did not interfere with the interaction of $A \beta O$ with its antibody and aptamer.

$0.01 \mathrm{pM}(10 \mathrm{fM})$, but the dual probe showed higher changes in current with all $\mathrm{A} \beta \mathrm{O}$ concentrations. This attainment attested to the good sensitivity of the sensor and was comparable to the current sensors used for determining AD (Table 1).

\section{Selectivity, Reproducibility and Stability for A $\mathrm{OO}$ Determination: High- Performance Analysis}

Specific identification of $\mathrm{A} \beta \mathrm{O}$ was monitored with three different control experiments, which included experiments without $\mathrm{A} \beta \mathrm{O}$, with nonimmune antibody and complementary aptamer sequences, and with $\alpha$-synuclein instead of $\mathrm{A} \beta \mathrm{O}$. These three control experiments did not give significant current responses, which confirmed specific $\mathrm{A} \beta \mathrm{O}$ detection (Figure 7A).

To mimic $\mathrm{A} \beta \mathrm{O}$ detection in real-life situations, different $\mathrm{A} \beta \mathrm{O}$ concentrations $(0.01,0.1,1,10$, and 100 $\mathrm{pM}$ ) were spiked into artificial CSF and dripped onto dual probe-modified surfaces for interaction. As shown in the figure, clear changes in the current response were noted with different $\mathrm{A} \beta \mathrm{O}$ concentrations spiked into CSF. There was no significant current response compared with the detection of $\mathrm{A} \beta \mathrm{O}$ in the presence or absence of CSF (Figure 7B). This means that $\mathrm{A} \beta \mathrm{O}$ was specifically recognized by the aptamer and antibody on the immobilized electrode surfaces. Reproducibility is mandatory confirmation in any sensor and is needed to obtain accurate results for high-performance target identification. Here, current responses with five different electrodes were monitored, including surfaces modified with APTMS nanohorns, dual antibody-aptamer probes, $\mathrm{PEH}-\mathrm{NH}_{2}$ and $\mathrm{A} \beta \mathrm{O}$.

\section{Conclusion}

This research involved studies of the Alzheimer's disease biomarker amyloid-beta oligomer $(\mathrm{A} \beta \mathrm{O})$ on a nanohornmodified electrode surface. A nanohorn was attached to the electrode surface through an amine linker, and then a dual probe of aptamer-antibody-modified Au urchin was attached to the nanohorn. This dual probe-modified surface improved the detection of $\mathrm{A} \beta \mathrm{O}$, and the current flow was compared with that seen with only antibody as the probe; the improved system realized a detection limit of $10 \mathrm{fM}$. Since the dual probe interacted with a higher number of $\mathrm{A} \beta \mathrm{Os}$, enhanced current changes were noticed at all $\mathrm{A} \beta \mathrm{O}$ concentrations used. Furthermore, control experiments failed to change the current flow, confirming the specific detection of $A \beta O$. In addition, spiking $A \beta O$ into the artificial CSF did not interfere with the detection of $\mathrm{A} \beta \mathrm{O}$, indicating the selective determination of $\mathrm{A} \beta \mathrm{O}$. This dual probe-modified electrode surface helps to identify $A \beta O$ and diagnose Alzheimer's disease.

\section{Acknowledgment}

SCBG was supported by a special grant (9001-00596) from Universiti Malaysia Perlis.

\section{Disclosure}

The authors report no conflicts of interest for this work.

\section{References}

1. Sun LP, Zhong Y, Gui J, Wang XW, Zhuang XR, Weng J. A hydrogel biosensor for high selective and sensitive detection of amyloid-beta oligomers. Int J Nanomedicine. 2018;13:843-856. doi:10.2147/IJN. S152163 
2. Pundir CS, Narwal V. Biosensing methods for determination of triglycerides: a review. Biosens Bioelectron. 2018;100:214-227. doi:10.1016/j.bios.2017.09.008

3. Bae JB, Lee S, Jung W, et al. Identification of Alzheimer's disease using a convolutional neural network model based on T1-weighted magnetic resonance imaging. Sci Rep. 2020;10(1):1-10. doi:10.1038/ s41598-020-79243-9

4. Azimzadeh M, Nasirizadeh N, Rahaie M, Naderi-Manesh H. Early detection of Alzheimer's disease using a biosensor based on electrochemically-reduced graphene oxide and gold nanowires for the quantification of serum microRNA-137. RSC Adv. 2017;7(88):5570 9-55719. doi:10.1039/C7RA09767K

5. Arslan J, Jamshed H, Qureshi H. Early Detection and Prevention of Alzheimer's Disease: role of Oxidative Markers and Natural Antioxidants. Front Aging Neurosci. 2020;12:1-7. doi:10.3389/ fnagi.2020.00231

6. Toyos-Rodríguez C, García-Alonso FJ, de la Escosura-Muñiz A. Electrochemical biosensors based on nanomaterials for early detection of alzheimer's disease. Sensors (Switzerland). 2020;20(17):1-43. doi:10.3390/s20174748

7. Liu D, Fu D, Zhang L, Sun L. Detection of amyloid-beta by FmocKLVFF self-assembled fluorescent nanoparticles for Alzheimer's disease diagnosis. Chin Chem Lett. 2020;2019. doi:10.1016/j.cclet.20 20.09.009.

8. Zhou Y, Zhang H, Liu L, et al. Fabrication of an antibody-aptamer sandwich assay for electrochemical evaluation of levels of $\beta$-amyloid oligomers. Sci Rep. 2016;6:1-8. doi:10.1038/s41598-016-0001-8

9. Sun L, Liu D, Fu D, Yue T, Scharre D, Zhang L. Fluorescent peptide nanoparticles to detect amyloid-beta aggregation in cerebrospinal fluid and serum for Alzheimer's disease diagnosis and progression monitoring. Chem Eng J. 2021;405:126733. doi:10.1016/j.cej.2020. 126733

10. Veloso AJ, Chow AM, Ganesh HVS, et al. Electrochemical immunosensors for effective evaluation of amyloid-beta modulators on oligomeric and fibrillar aggregation processes. Anal Chem. 2014;86 (10):4901-4909. doi:10.1021/ac500424t

11. Yi X, Feng C, Hu S, Li H, Wang J. Surface plasmon resonance biosensors for simultaneous monitoring of amyloid-beta oligomers and fibrils and screening of select modulators. Analyst. 2016; 141:331-336. doi:10.1039/C5AN01864A

12. Wennmalm S, Chmyrov V, Widengren J, Tjernberg L. Highly Sensitive FRET-FCS Detects Amyloid $\beta$-Peptide Oligomers in Solution at Physiological Concentrations. Anal Chem. 2015;87 (23):11700-11705. doi:10.1021/acs.analchem.5b02630

13. Zhao J, Chang W, Liu L, et al. Graphene oxide-gold nanoparticle-aptamer complexed probe for detecting amyloid beta oligomer by ELISA-based immunoassay. J Immunol Methods. 2021;489:112942. doi:10.1016/j.jim.2020.112942

14. Liu F, Zhang J, Chen R, Chen L, Deng L. Highly effective colorimetric and visual detection of ATP by a DNAzyme-aptamer sensor Chem Biodivers. 2011;8(2):311-316. doi:10.1002/cbdv.201000130

15. Gopinath SCB, Sakamaki Y, Kawasaki K, Kumar PKR. An Efficient RNA Aptamer against Human Influenza B Virus Hemagglutinin. J Biochem. 2006;139(5):837-846. doi:10.1093/jb/mvj095

16. Gopinath SCB, Misono TS, Kumar PKR. Prospects of Ligand-Induced Aptamers. Crit Rev Anal Chem. 2008;38(1):34-47. doi:10.1080/10408340701804558

17. Gopinath SCB, Shikamoto Y, Mizuno H, Kumar P. A Potent Anti-Coagulant RNA Aptamer Inhibits Blood Coagulation by Specifically Blocking the Extrinsic Clotting Pathway. Thromb Haemost. 2006;95:767-771. doi:10.1160/TH06-01-0047

18. Lakshmipriya T, Fujimaki M, Gopinath SCB, Awazu K. Generation of anti-influenza aptamers using the systematic evolution of ligands by exponential enrichment for sensing applications. Langmuir. 2013;29(48):15107-15115. doi:10.1021/la4027283
19. Gopinath SCB, Lakshmipriya T, Awazu K. Colorimetric detection of controlled assembly and disassembly of aptamers on unmodified gold nanoparticles. Biosens Bioelectron. 2014;51:115-123. doi:10.1016/j. bios.2013.07.037

20. Lakshmipriya T, Horiguchi Y, Nagasaki Y. Co-immobilized poly (ethylene glycol)-block-polyamines promote sensitivity and restrict biofouling on gold sensor surface for detecting factor IX in human plasma. Analyst. 2014;139(16):3977-3985. doi:10.1039/C4AN00 $168 \mathrm{~K}$

21. Jarczewska M, Malinowska E. The application of antibody-aptamer hybrid biosensors in clinical diagnostics and environmental analysis. Anal Methods. 2020;12(25):3183-3199. doi:10.1039/D0AY00678E

22. Serban B-C, Bumbac M, Buiu O, Cobianu C, Brezeanu M, Nicolescu C. Carbon Nanohorns and Their Nanocomposites: synthesis, Properties and Applications. a Concise Review. Ann Acad Rom Sci Ser Sci Technol Inf. 2018;11(2):5.

23. Zhu S, Xu G. Single-walled carbon nanohorns and their applications. Nanoscale. 2010;2(12):2538-2549. doi:10.1039/c0nr00387e

24. Zhu G, Sun H, Zou B, et al. Electrochemical sensing of 4-nitrochlorobenzene based on carbon nanohorns/graphene oxide nanohybrids. Biosens Bioelectron. 2018;106:136-141. doi:10.1016/j. bios.2018.01.058

25. Zhu G, Fiston MN, Qian J, Kingsford OJ. Highly sensitive electrochemical sensing of: para -chloronitrobenzene using a carbon nanohorn-nanotube hybrid modified electrode. Anal Methods. 2019;11:1125-1130. doi:10.1039/C8AY02680G

26. Tsukakoshi K, Abe K, Sode K, Ikebukuro K. Selection of DNA aptamers that recognize $\alpha$-synuclein oligomers using a competitive screening method. Anal Chem. 2012;84(13):5542-5547. doi:10.1021/ ac300330g

27. Liu L, He Q, Zhao F, et al. Competitive electrochemical immunoassay for detection of $\beta$-amyloid (1-42) and total $\beta$-amyloid peptides using p-aminophenol redox cycling. Biosens Bioelectron. 2014;51: 208-212. doi:10.1016/j.bios.2013.07.047

28. Hegnerová K, Bocková M, Vaisocherová H, et al. Surface plasmon resonance biosensors for detection of Alzheimer disease biomarker. Sens Actuators B Chem. 2009;139:69-73. doi:10.1016/j.snb.2008. 09.006

29. Ramanathan S, Gopinath SCB, Arshad MKM, et al. Aluminosilicate Nanocomposite on Genosensor: a Prospective Voltammetry Platform for Epidermal Growth Factor Receptor Mutant Analysis in Non-small Cell Lung Cancer. Sci Rep. 2019. doi:10.1038/s41598019-53573-9

30. Letchumanan I, Gopinath SCB, Md arshad MK, Anbu P, Lakshmipriya T. Gold nano-urchin integrated label-free amperometric aptasensing human blood clotting factor IX: a prognosticative approach for "Royal disease.". Biosens Bioelectron. 2019;131:128-135. doi:10.1016/j.bios.2019.02.006

31. Lakshmipriya T, Fujimaki M, Gopinath SCB, Awazu K, Horiguchi Y, Nagasaki Y. A high-performance waveguide-mode biosensor for detection of factor IX using PEG-based blocking agents to suppress non-specific binding and improve sensitivity. Analyst. 2013;138 (10):2863. doi:10.1039/c3an00298e

32. Nagasaki Y. Construction of a densely poly(ethylene glycol)-chaintethered surface and its performance. Polym J. 2011;43(12):949-958. doi:10.1038/pj.2011.93

33. Cui M,Ono M,Watanabe H,Kimura H,Liu B,Saji H. Smart nearinfrared fluorescence probes with donor-acceptor structure for in vivo detection of $\beta$-amyloid deposits. J Am Chem Soc. 2014;136 (9):3388-94.

34. Kutovyi Y, Hlukhova H, Boichuk N, Menger M, Offenhäusser A, Vitusevich S. Amyloid-beta peptide detection via aptamer-functionalized nanowire sensors exploiting single-trap phenomena. Biosens Bioelectron. 2020;154(November 2019). 
35. Qin H, Gao X, Yang X, Cao W, Liu S. A label-free and signal-on electrochemiluminescence strategy for sensitive amyloid-beta assay. Biosens Bioelectron. 2019;141:111438.

36. Qin J, Cho M, Lee Y. Ultrasensitive Detection of Amyloid- $\beta$ Using Cellular Prion Protein on the Highly Conductive Au NanoparticlesPoly(3,4-ethylene dioxythiophene)-Poly(thiophene-3-acetic acid) Composite Electrode. Anal Chem. 2019;91(17):11259-65.

37. Zhang Y, Figueroa-Miranda G, Zafiu C, Willbold D, Offenhäusser A, Mayer D. Amperometric Aptasensor for Amyloid- $\beta$ Oligomer Detection by Optimized Stem-Loop Structures with an Adjustable Detection Range. ACS Sensors. 2019;4(11):3042-50.
38. Chou IH, Benford M, Beier HT, Cotè GL, Wang M, Jing N, et al. Nanofluidic biosensing for $\beta$-amyloid detection using surface enhanced raman spectroscopy. Nano Lett. 2008;8(6):1729-35.

39. Xia N, Zhou B, Huang N, Jiang M, Zhang J, Liu L. Visual and fluorescent assays for selective detection of beta-amyloid oligomers based on the inner filter effect of gold nanoparticles on the fluorescence of CdTe quantum dots. Biosens Bioelectron. 2016;85:625-32.

40. Chongzhao R, Xiaoyin X, Raymond SB, Ferrara BJ, Neal K, Bacskai BJ, et al. Design, synthesis, and testing of difluoroboronderivatized curcumins as near-infrared probes for in vivo detection of amyloid- $\beta$ deposits. J Am Chem Soc. 2009;131(42):15257-61.

\section{Publish your work in this journal}

The International Journal of Nanomedicine is an international, peerreviewed journal focusing on the application of nanotechnology in diagnostics, therapeutics, and drug delivery systems throughout the biomedical field. This journal is indexed on PubMed Central, MedLine, CAS, SciSearch ${ }^{\mathbb{R}}$, Current Contents ${ }^{\mathbb{R}} /$ Clinical Medicine, $^{2}$
Journal Citation Reports/Science Edition, EMBase, Scopus and the Elsevier Bibliographic databases. The manuscript management system is completely online and includes a very quick and fair peer-review system, which is all easy to use. Visit http://www.dovepress.com/ testimonials.php to read real quotes from published authors. 